\title{
Doxycycline targets aldehyde dehydrogenase-positive breast cancer stem cells
}

\author{
CHANG-CHING LIN ${ }^{1}$, MIAO-CHIA LO ${ }^{1}$, REBECCA R. MOODY ${ }^{1,2}$, NICHOLAS O. STEVERS $^{1}$, \\ SAMANTHA L. TINSLEY ${ }^{1}$ and DUXIN SUN ${ }^{1,2}$ \\ ${ }^{1}$ Department of Pharmaceutical Sciences, College of Pharmacy and ${ }^{2}$ Chemical Biology Program, \\ University of Michigan, Ann Arbor, MI 48109, USA
}

Received November 8, 2017; Accepted March 20, 2018

DOI: $10.3892 /$ or.2018.6337

\begin{abstract}
Targeting cancer stem cells (CSCs) is a key strategy to prevent cancers from developing drug resistance and metastasis. Mitochondria have been reported to be a vulnerability of CSCs by multiple studies. Here, we report that doxycycline, functioning as an inhibitor of mitochondrial biogenesis, can effectively target breast cancer stem cells (BCSCs). Our results revealed that doxycycline significantly decreased the frequency of aldehyde dehydrogenase-positive $\left(\mathrm{ALDH}^{+}\right)$ BCSCs as well as mammosphere formation efficiency in $\mathrm{HER}^{+}$and triple-negative breast cancer (TNBC) subtypes. Doxycycline also ameliorated paclitaxel-induced enrichment of $\mathrm{ALDH}^{+} \mathrm{BCSC}$ in TNBC. Mechanistically, we showed that doxycycline decreased the level of reactive oxygen species and their downstream p38 MAPK pathway. In agreement with the key role for p38 in maintaining BCSCs, a specific inhibitor targeting this MAPK pathway significantly decreased the number of $\mathrm{ALDH}^{+}$cells. Doxycycline is a FDA-approved drug with minor and limited side-effects. Given doxycycline's low toxicity and strong effect on BCSC inhibition, we report that doxycycline should be safe to be used concomitantly with chemotherapy drugs to eradicate both CSCs and bulk tumor cells.
\end{abstract}

\section{Introduction}

With an estimated 230,000 new cases and 40,000 deaths in 2013, breast cancer has the highest incidence and is the second leading cause of cancer-related death among women in the United States (1). Four subtypes of breast cancers, namely

Correspondence to: Dr Duxin Sun or Dr Miao-Chia Lo, Department of Pharmaceutical Sciences, College of Pharmacy, University of Michigan, 1600 Huron Parkway, Ann Arbor, MI 48109, USA

E-mail: duxins@umich.edu

E-mail:miaoclo@umich.edu

Key words: doxycycline, breast cancer, aldehyde dehydrogenase, cancer stem cells, mitochondria, reactive oxygen species, p38 MAPK luminal A, luminal B, HER2 ${ }^{+}$and basal-like (significantly but not completely overlaps with the triple-negative breast cancer, TNBC), are classified according to the intrinsic gene expression profile $(2,3)$. While the luminal subtypes respond well to hormone therapies, over $50 \%$ of patients with HER $2^{+}$breast cancer develop trastuzumab-resistance within 1 to 2 years of treatment $(4,5)$. More than $70 \%$ of TNBC patients have residual invasive disease after neoadjuvant chemotherapy and are at high risk of disease relapse (6). Recent evidence supports that a small fraction of cancer cells, termed cancer stem cells (CSCs), are capable of self-renewing and differentiating into non-stem cancer cells and are responsible for tumor initiation, drug resistance and metastasis (7-10). Therefore, combining CSC-targeting agents with conventional chemotherapies seems to be a promising strategy for eradicating both CSCs and bulk tumor cells $(11,12)$.

Reprogramming of energy metabolism is one of the hallmarks of cancer (13). Over 80 years ago, Otto Warburg observed that cancer cells favored aerobic glycolytic metabolism in the presence of oxygen (14). Warburg hypothesized that cancer resulted from impaired cellular mitochondrial metabolism. It is clear now that the Warburg effect is not due to the impairment of mitochondrial function in tumors. Indeed, depletion of mitochondrial DNA has been shown to decrease colony formation in soft agar and tumor initiation in mice (15-19), which are the key indicators of CSCs. Recent studies have also demonstrated that mitochondrial features of CSCs differ from those of non-stem cancer cells (20-22), and attenuating mitochondrial metabolism could suspend tumor metastasis and prolong tumor latency in xenograft models $(19,23)$. This phenomenon indicates that mitochondria are functionally indispensable to sustaining CSCs. Therefore, targeting mitochondria is emerging as a new strategy for eradicating CSCs.

Doxycycline is a commonly used tetracycline analogue of antibiotics. With ideal pharmacokinetics and minor side effects, doxycycline has been used in clinics for five decades. The mechanism of doxycycline's action is binding to mitochondrial ribosome, which then disrupts the biogenesis of bacterial mitochondria. In addition to bacterial mitochondria, doxycycline has also been reported to affect mitochondria in eukaryotes (24). In cancer, doxycycline was found to inhibit the self-renewal ability of CSCs in many types of cancer, 
including breast cancer (25-28), indicating the potentiality of using the 'old' antibiotic for a new treatment-targeting CSCs.

Although doxycycline-mediated CSC inhibition has been linked to mitochondria $(20,24,25)$, it remains unknown what type of CSCs doxycycline could inhibit. Breast cancer stem cells (BCSCs) can transition between two phenotypic states. One is a more proliferative epithelial-like state characterized by the expression of the CSC marker aldehyde dehydrogenase (ALDH) and the other is a more quiescent mesenchymal-like state characterized by the expression $\mathrm{CD}_{4} 4^{+} / \mathrm{CD} 24^{-}$(29). In this study, we selected BT474, SK-BR-3, SUM149, and SUM159 breast cancer cell lines to examine doxycycline's effects on BCSCs. BT474 and SK-BR-3 are both HER2 ${ }^{+}$breast cancer cell lines and according to the literature and our previous publication, this subtype has a higher number of $\mathrm{ALDH}^{+}$ epithelial-like BCSCs compared to other subtypes but does not have the $\mathrm{CD} 44^{+} / \mathrm{CD} 24^{-}$mesenchymal-like BCSC population (30,31). In contrast, SUM159 is a Claudin-low TNBC cell line, which has a high percentage of mesenchymal-like bulk tumor cells that are also $\mathrm{CD}_{4} 4^{+} / \mathrm{CD} 24^{-}(30)$. As a result, the CD $44^{+} / \mathrm{CD} 24^{-}$markers cannot be used to define the mesenchymal-like BCSCs in the Claudin-low subtype. SUM149, on the other hand, is a basal-like TNBC and has both $\mathrm{ALDH}^{+}$

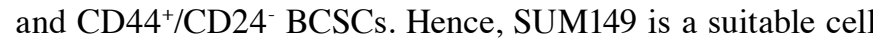
line for testing the effects of doxycycline on $\mathrm{ALDH}^{+}$as well as $\mathrm{CD} 44^{+} / \mathrm{CD} 24^{-}$BCSC populations.

In the present study, we report that doxycycline can reduce the $\mathrm{ALDH}^{+} \mathrm{BCSC}$ population. Mechanistically, our results suggest that doxycycline inhibits $\mathrm{ALDH}^{+} \mathrm{BCSC}$ via inhibiting reactive oxygen species (ROS) production and their downstream p38 MAPK signaling pathway.

\section{Materials and methods}

Cell lines and chemicals. BT474 (ATCC, Manassas, VA, USA) and SK-BR-3 (ATCC) cells were grown in RPMI-1640 (Invitrogen; Thermo Fisher Scientific, Inc., Waltham, MA, USA) containing 10\% FBS and $1 \mathrm{X}$ antibiotic-antimycotic (Invitrogen; Thermo Fisher Scientific, Inc.). SUM149 and SUM159 cell lines were kindly provided by Dr Max Wicha (University of Michigan, Ann Arbor, MI, USA). SUM149 and SUM159 cells were grown in F12 (Invitrogen; Thermo Fisher Scientific, Inc.) containing 5\% FBS, $1 \mathrm{X}$ antibiotic-antimycotic, $5 \mu \mathrm{g} / \mathrm{ml}$ of insulin (Invitrogen; Thermo Fisher Scientific, Inc.) and $1 \mu \mathrm{g} / \mathrm{ml}$ of hydrocortison (Sigma-Aldrich, St. Louis, MO, USA). Cells were cultured in a $5 \% \mathrm{CO}_{2}$ incubator at $37^{\circ} \mathrm{C}$. p38 MAPK inhibitor SB203580 was purchased from Cayman Chemical Co. (Ann Arbor, MI, USA). Doxycycline hyclate was purchased from Sigma-Aldrich.

Mammosphere formation assay. Mammosphere formation was performed as previously described (32). Single cells were seeded in low-attachment 6-well plates (Corning Inc., Corning, NY, USA) at a density of 5,000 cells/well. Cells were cultured in $2 \mathrm{ml}$ of MammoCult ${ }^{\mathrm{TM}}$ (Stemcell Technologies, Inc., Vancouver, BC, Canada) with doxycycline from 0-10 $\mu \mathrm{M}$. Doxycycline was replenished every 2 days, and mammospheres were counted on day 6 . To test the self-renewal ability of CSCs, secondary mammosphere formation was performed in the absence of doxycycline. Briefly, primary spheres were dissociated to single cells enzymatically (trypsin) and mechanically (23G needle). Secondary mammosphere formation was performed by plating 5,000 cells/well of the dissociated single cells from the primary mammospheres.

Aldefluor assay. Cells were treated with $0,0.1,1$ or $10 \mu \mathrm{g} / \mathrm{ml}$ of doxycycline for 7 days. The aldehyde dehydrogenase (ALDH) activity was then determined by Aldefluor assay (StemCell Technologies Inc., Cambridge, MA, USA) according to the manufacturer's instructions. Diethylaminobenzaldehyde (DEAB) was used as a negative control for gating. To test the importance of the $\mathrm{p} 38$ pathway in maintaining $\mathrm{ALDH}^{+} \mathrm{BCSCs}$, BT474 cells were treated with SB203580, a p38-specific inhibitor, for 2 days and then Aldefluor assay was conducted. To inhibit chemotherapy-induced Aldefluor-positive CSCs, cells were pretreated with $10 \mu \mathrm{M}$ of doxycycline for 3 days, and then were treated with a combination of doxycycline and $10 \mathrm{nM}$ of paclitaxel for another 4 days.

CD44 and CD24 analysis. Cells were treated with $0,0.1,1$ or $10 \mu \mathrm{g} / \mathrm{ml}$ of doxycycline for 7 days, and then were harvested for CD44 (BD Biosciences, San Jose, CA, USA) and CD24 (BioLegend, Inc., San Diego, CA, USA) antibody staining. The cells were then analyzed by flow cytometry.

Analysis of reactive oxygen species (ROS). Cells were treated with $10 \mu \mathrm{g} / \mathrm{ml}$ of doxycycline for 7 days and then ROS were determined by a 2',7'-dichlorofluorescin diacetate (DCFDA)-based kit (Abcam, Cambridge, MA, USA) according to the manufacturer's instructions. Briefly, the cells were incubated with $20 \mu \mathrm{M}$ of DCFDA at $37^{\circ} \mathrm{C}$ for $30 \mathrm{~min}$. Samples were then spiked with $300 \mu \mathrm{l}$ of ice-cold $1 \mathrm{X}$ buffer containing DAPI and kept on ice before the ROS level was measured by flow cytometry.

Immunoblotting. Breast cancer cells were treated with $0,0.1$, 1 or $10 \mu \mathrm{g} / \mathrm{ml}$ of doxycycline for 7 days. Cells were then lysed using RIPA buffer containing proteinase inhibitor cocktail (Thermo Fisher Scientific, Inc.) and Calbiochem ${ }^{\circledR}$ phosphatase inhibitors (MilliporeSigma, Burlington, MA, USA). Proteins were separated by SDS-PAGE and probed with antibodies. Phosphorylated p38 MAPK (1:1,000; cat. no. 4511; rabbit mAb), p38 MAPK (1:1,000; cat. no. 8690; rabbit mAb) and vinculin $(1: 2,000$; cat. no. 13901; rabbit $\mathrm{mAb})$ antibodies were purchased from Cell Signaling Technology, Inc. (Danvers, MA, USA).

Statistical analysis. Two-tailed Student's t-test was used to compare the statistical difference between two groups. One-way ANOVA was used if the comparison involved more than two groups. A P-value $<0.05$ was considered to indicate statistical significance.

\section{Results}

Doxycycline inhibits $A L D H^{+} B C S C s$. To test doxycycline's ability to inhibit $\mathrm{ALDH}^{+} \mathrm{BCSCs}$, we treated breast cancer cell lines with doxycycline and then measured ALDH activity in these cells. ALDH is an important biomarker of CSCs in many types of cancer (33). In breast cancer, cells with high ALDH 

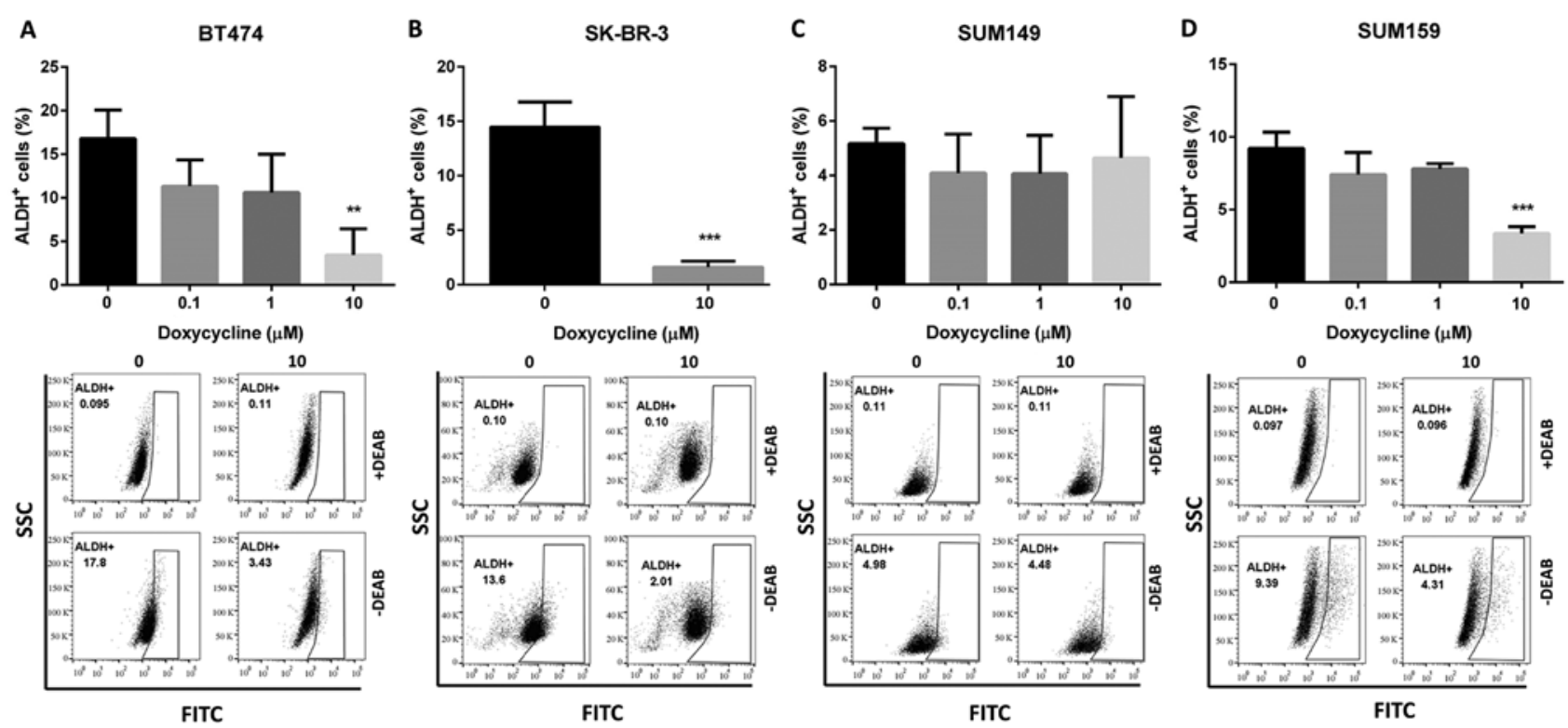

Figure 1. Doxycycline decreases the ALDH ${ }^{+}$BCSC population. ALDH activities in (A) BT474 (B) SK-BR-3 (C) SUM149 and (D) SUM159 cells treated with different concentrations of doxycycline for 7 days were determined by Aldefluor assays. Results are expressed as mean $\pm S D\left(n=3,{ }^{*} P<0.05,{ }^{* *} \mathrm{P}<0.01\right.$, ${ }^{* * * *} \mathrm{P}<0.001$, one-way ANOVA). BCSC, breast cancer stem cell.

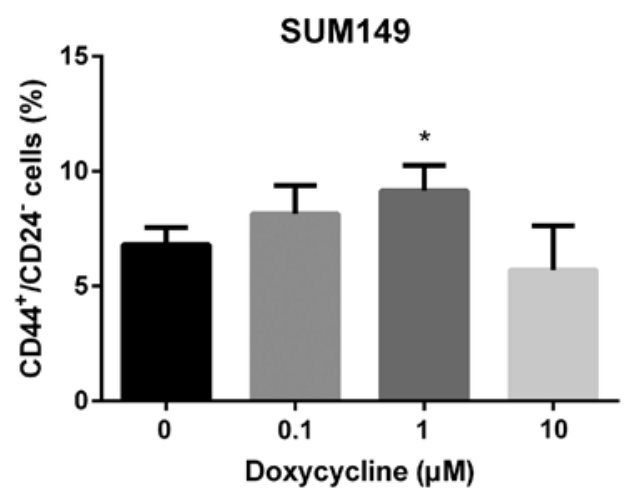

Figure 2. Doxycycline does not affect the $\mathrm{CD} 44^{+} / \mathrm{CD} 24-\mathrm{BCSC}$ population. Flow cytometric analysis of $\mathrm{CD} 44^{+} / \mathrm{CD} 24^{-}$BCSCs in SUM149 cells treated with different concentrations of doxycycline for 7 days. Results are expressed as mean $\pm \mathrm{SD}\left(\mathrm{n}=3,{ }^{*} \mathrm{P}<0.05,{ }^{* *} \mathrm{P}<0.01,{ }^{* * * *} \mathrm{P}<0.001\right.$, one-way ANOVA). BCSC, breast cancer stem cell.

activity have self-renewal ability to regenerate tumors that recapitulate the heterogeneity of the parental tumors (8). Our results demonstrated that doxycycline at $10 \mu \mathrm{M}$ significantly decreased the percentage of cells with high ALDH activity in the BT474, SK-BR-3 and SUM159 cells (Fig. 1). These results suggested that doxycycline could be used to target $\mathrm{ALDH}^{+}$BCSCs. However, in SUM149 cells, doxycycline did not decrease $\mathrm{ALDH}^{+}$(Fig. 1) or $\mathrm{CD}_{4} 4^{+} / \mathrm{CD} 24^{-}$(Fig. 2) BCSCs. This result may be due to the characteristics of the SUM149 cell line (see Discussion).

To further confirm whether doxycycline could functionally inhibit BCSCs, we treated BT474, SUM149 and SUM159 cells with various concentrations of doxycycline in the primary mammmosphere culture. Mammosphere formation is an in vitro surrogate assay to evaluate self-renewal ability of BCSCs. In BT474 and SUM159, primary mammosphere formation was significantly inhibited by doxycycline in a concentration-dependent manner, whereas in SUM149, it was inhibited only at $10 \mu \mathrm{M}$ (Fig. 3). The primary mammospheres were then dissociated and reseeded to form secondary mammospheres in the absence of doxycycline. In the secondary mammosphere culture, a 50\% decrease in mammospheres was observed in the $10 \mu \mathrm{M}$ doxycycline-pretreated BT474 and SUM159 cells (Fig. 3), indicating that doxycycline could inhibit the self-renewal ability of BCSCs in these cell lines.

Doxycycline inhibits reactive oxygen species and their downstream p38 signaling. In mammalian cells, doxycycline inhibits mitochondrial biogenesis by binding to $28 \mathrm{~S}$ small mitochondrial ribosome $(24,34)$. Mitochondria is the main organelle of ROS generation. High mitochondrial mass (20) and elevated ROS levels (35) have been reported to sustain $\mathrm{ALDH}^{+} \mathrm{CSCs}$. We demonstrated that doxycycline treatment significantly inhibited $\mathrm{ALDH}^{+}$BCSCs (Fig. 1). Therefore, we hypothesized that doxycycline inhibited $\mathrm{ALDH}^{+} \mathrm{BCSCs}$ via ROS attenuation. To test if doxycycline could decrease cellular ROS levels, we performed DCFDA assays after doxycycline treatment and analyzed samples by flow cytometry. As expected, a significant decrease in ROS levels was observed in the doxycycline-treated cells (Fig. 4).

Next, we examined whether the p38 MAPK signaling downstream of ROS was affected by doxycycline. We found that doxycycline treatment resulted in a decrease in p38 phosphorylation in a dose-dependent manner in the BT474 and SUM159 cell lines (Fig. 5A and B). To further test the correlation between p38 MAPK signaling and $\mathrm{ALDH}^{+}$ BCSCs, we treated BT474 cells with a p38 MAPK-specific inhibitor SB203580 and then performed the Aldefluor assay. The result showed that SB203580 abolished ALDH activity (Fig. 5C), indicating that p38 MAPK plays a key role in $\mathrm{ALDH}^{+} \mathrm{BCSC}$ maintenance, which is targeted by doxycycline treatment. 

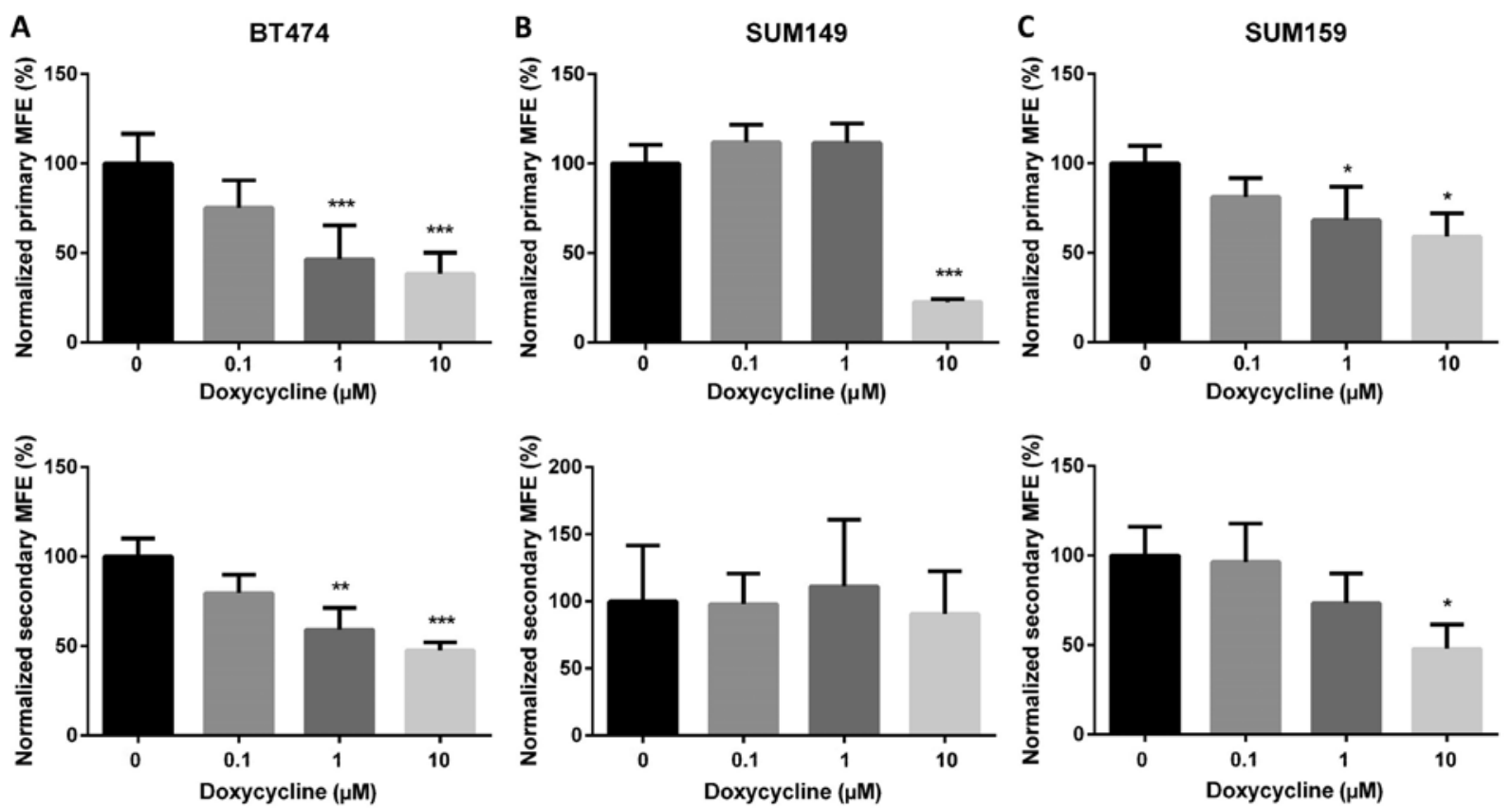

Figure 3. Doxycycline inhibits the self-renewal ability of breast cancer cells. Relative mammosphere formation efficiencies in (A) BT474, (B) SUM149 and (C) SUM159 cells were shown as the mean $\pm \mathrm{SD}\left(\mathrm{n}=3,{ }^{*} \mathrm{P}<0.05,{ }^{* *} \mathrm{P}<0.01,{ }^{* * *} \mathrm{P}<0.001\right.$, one-way ANOVA). Cells were treated with different concentrations of doxycycline in the primary mammosphere cultures (top panels) and then re-seeded in the secondary mammosphere cultures (bottom panels) in the absence of doxycycline.

A
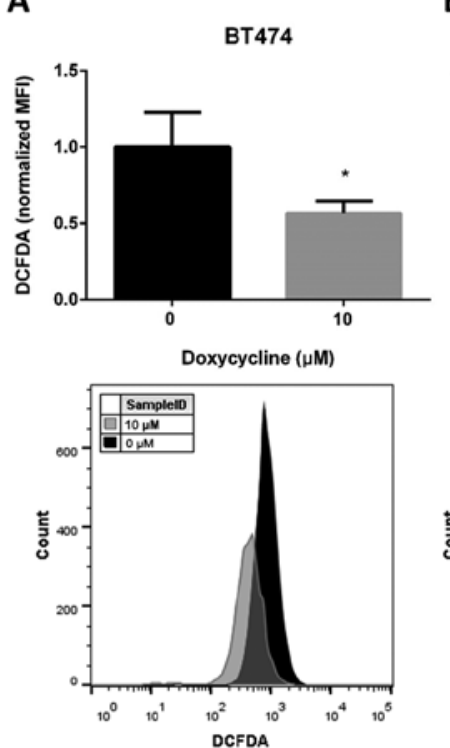

B
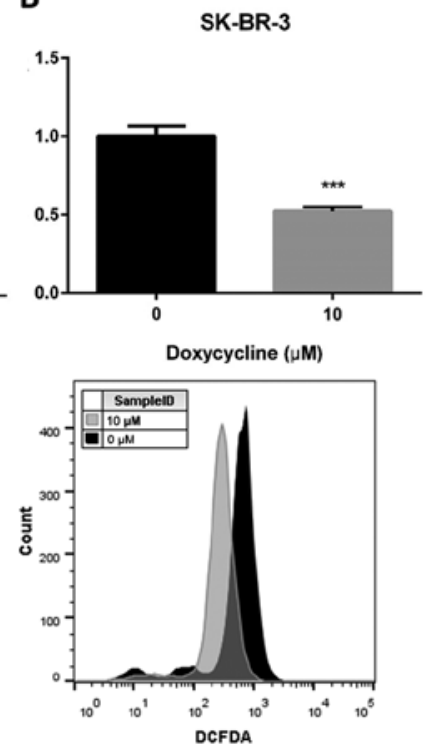

C
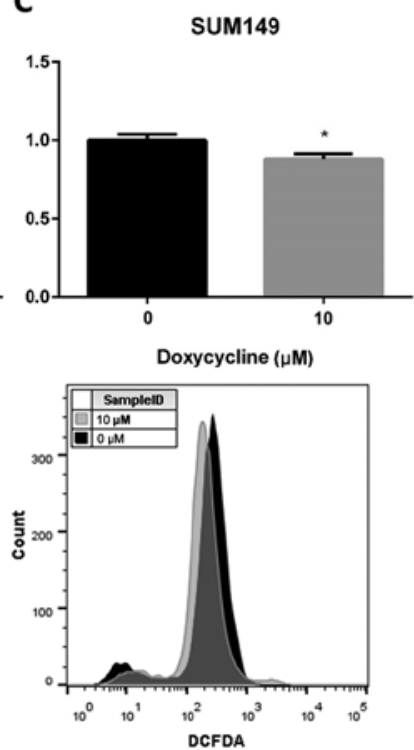

D
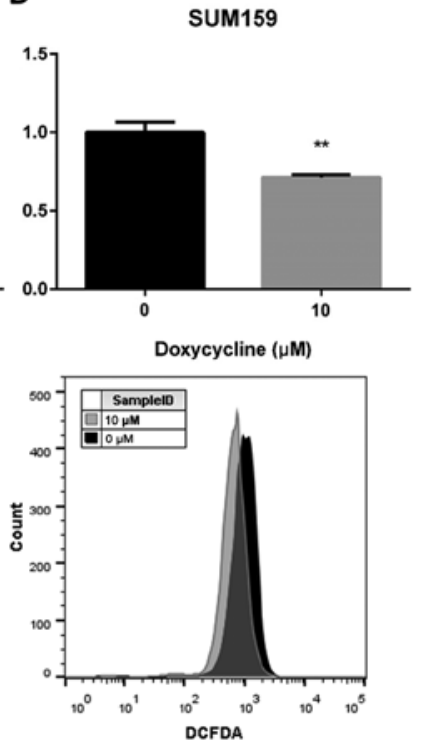

Figure 4. Doxycycline decreases the ROS levels in breast cancer cells. ROS levels in (A) BT474, (B) SK-BR-3, (C) SUM149 and (D) SUM159 cells treated with doxycycline $(10 \mu \mathrm{M})$ or vehicle control for 7 days were determined by DCFDA assays. Results are expressed as normalized mean fluorescence intensity $(\mathrm{MFI}) \pm \mathrm{SD}\left(\mathrm{n}=3,{ }^{*} \mathrm{P}<0.05,{ }^{* *} \mathrm{P}<0.01,{ }^{* * *} \mathrm{P}<0.001\right.$, Student's t-test $)$. ROS, reactive oxygen species.

Doxycycline attenuates paclitaxel-induced enrichment of $A L D H^{+} B C S C s$. Paclitaxel has been reported to kill the bulk of tumor cells, yet enriching $\mathrm{ALDH}^{+} \mathrm{CSC}$ s via elevating the ROS level (35). To ascertain whether doxycycline could ameliorate paclitaxel-induced enrichment of $\mathrm{ALDH}^{+}$ BCSCs, SUM159 cells were pre-treated with doxycycline and then in combination with paclitaxel. In agreement with the previous report, paclitaxel treatment resulted in approximately 4 times more $\mathrm{ALDH}^{+} \mathrm{BCSCs}$ as compared to the vehicle control. However, this enrichment of $\mathrm{ALDH}^{+}$ BCSCs induced by paclitaxel was significantly inhibited when cells were pre-treated and later co-treated with doxycycline (Fig. 6).

\section{Discussion}

Recent studies have demonstrated that metastasis and drug resistance of cancer are driven by small subpopulations of cells 
A

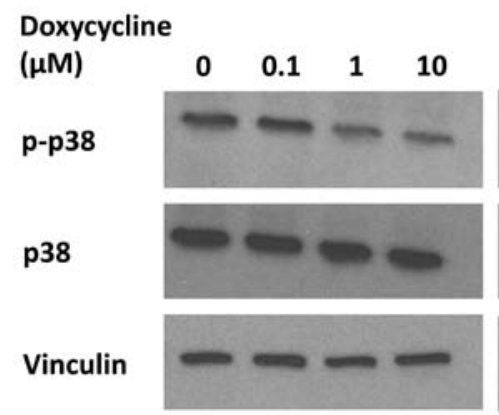

B

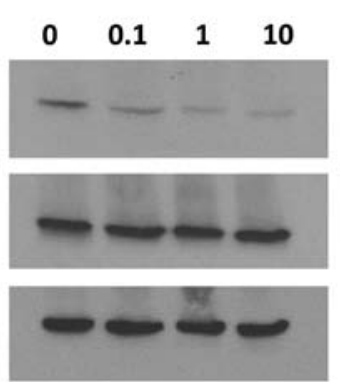

C

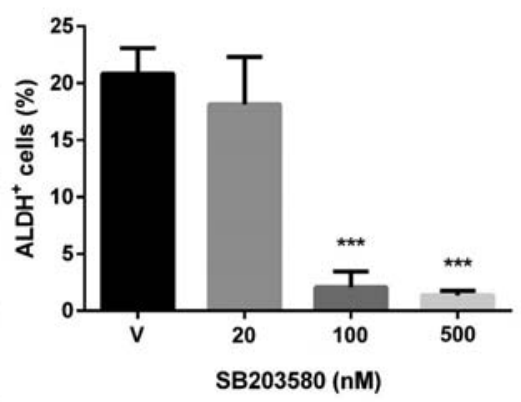

Figure 5. Doxycycline inhibits ALDH ${ }^{+}$BCSCs via blocking the p38 MAPK pathway. Western blot analysis of phosphorylated (p)-p38 and p38 in (A) BT474 and (B) SUM159 cells treated with different concentrations of doxycycline for 5 days. Vinculin was used as a loading control. Doxycycline treatment deceased the phosphorylation of p38 MAPK. (C) Aldefluor assays of BT474 cells treated with different concentrations of SB203580, a p38 MAPK-specific inhibitor for 2 days. SB203580 decreased the $\mathrm{ALDH}^{+}$BCSC population. Results are expressed as the mean $\pm \mathrm{SD}\left(\mathrm{n}=3,{ }^{*} \mathrm{P}<0.05,{ }^{* *} \mathrm{P}<0.01,{ }^{* * * *} \mathrm{P}<0.001\right.$, one-way $\left.\mathrm{ANOVA}\right)$. BCSCs, breast cancer stem cells; $\mathrm{V}$, vehicle.
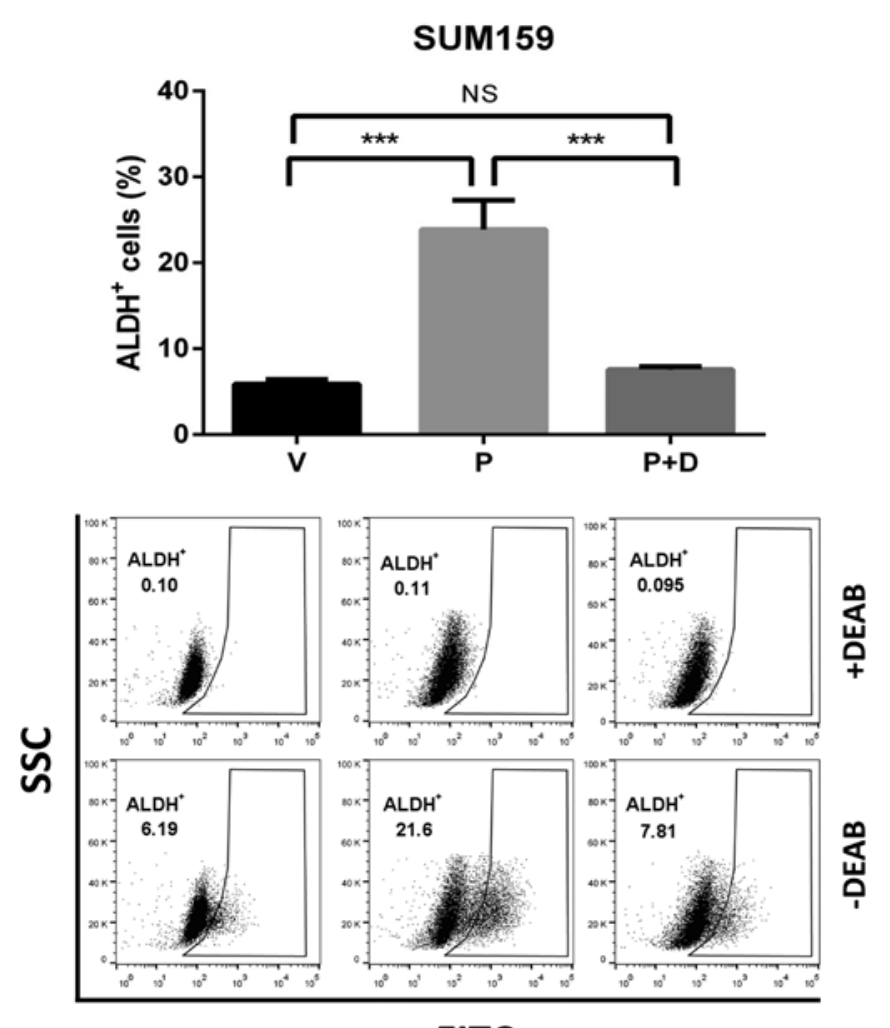

FITC

Figure 6. Doxycycline ameliorates paclitaxel-induced enrichment of $\mathrm{ALDH}^{+}$ BCSCs. ALDH activities in SUM159 cells receiving vehicle control (V), paclitaxel $(10 \mathrm{nM})(\mathrm{P})$ or paclitaxel $(10 \mathrm{nM})$ with doxycycline $(10 \mu \mathrm{M})$ pre-treatment $(\mathrm{P}+\mathrm{D})$ were determined by Aldefluor assays. Results are expressed as the mean $\pm \mathrm{SD}\left(\mathrm{n}=3,{ }^{*} \mathrm{P}<0.05,{ }^{* *} \mathrm{P}<0.01,{ }^{* * *} \mathrm{P}<0.001\right.$, one-way ANOVA). BCSCs, breast cancer stem cells; NS, not significant.

termed cancer stem cells (CSCs). CSCs are therefore emerging as important therapeutic targets for cancer treatment. In contrast to conventional cytotoxic chemotherapy which aims to kill the bulk of the tumor, CSC targeting therapy focuses on blocking specific signaling pathways which CSCs rely on. Thus, combining chemotherapy and CSC targeting therapy could help reach the goal of eradicating the entire tumor. In the present study, we found that doxycycline significantly decreased $\mathrm{ALDH}^{+} \mathrm{BCSC}$ by inhibiting MAPK signaling, the downstream pathway of ROS. While applied in combination with paclitaxel, doxycycline also attenuated paclitaxel-induced enrichment of $\mathrm{ALDH}^{+} \mathrm{BCSCs}$, implying the potentiality of combining the two drugs for removing both the bulk of cancer cells and CSCs.

High mitochondrial mass is associated with the $\mathrm{ALDH}^{+} \mathrm{CSC}$ population (20). Since doxycycline has been shown to interrupt mitochondrial biogenesis in eukaryotic systems (24), we hypothesized that doxycycline can be used as an inhibitor for $\mathrm{ALDH}^{+} \mathrm{CSCs}$. The hypothesis is supported by our results of aldefluor and mammosphere formation assays. However, we also found that doxycycline failed to decrease the $\mathrm{CD} 44^{+} / \mathrm{CD} 24^{-}$BCSC population (Fig. 2). $\mathrm{CD} 44^{+} / \mathrm{CD} 24^{-}$are cell-surface markers acquired by epithelial cancer cells when they undergo epithelial-to-mesenchymal transition (EMT), a developmental program that enriches CSCs (36). CD44+/CD24- EMT CSCs have characteristics that are distinct from those of $\mathrm{ALDH}^{+} \mathrm{CSC}$. Unlike proliferative and epithelial-like $\mathrm{ALDH}^{+} \mathrm{CSCs}, \mathrm{CD} 44^{+} / \mathrm{CD} 24^{-}$EMT CSCs are quiescent and mesenchymal-like $(29,37)$. Recent studies have reported that doxycycline can inhibit the propagation of mitochondrial-related hypoxic CSCs (27), whereas doxycycline-resistance may occur when cancer cells switch to a purely glycolytic phenotype (28). The relationship between CD $44^{+} / \mathrm{CD} 24^{-}$EMT CSCs and the glycolytic phenotype is yet to be determined. Nonetheless, it is likely that only mitochondrial-driven $\mathrm{ALDH}^{+} \mathrm{CSCs}$ but not $\mathrm{CD}^{4} 4^{+} / \mathrm{CD} 24^{-}$EMT CSCs are sensitive to doxycycline.

Mitochondria are an important source of ROS generation in most mammalian cells (38). ROS play an important role in stabilizing hypoxia-induced factor $1 \alpha$ (HIF-1 $\alpha$ ), which is known to induce $\mathrm{ALDH}^{+} \mathrm{CSCs}(35,39,40)$. Studies have shown that the p38 MAPK pathway, a downstream pathway of ROS, is required for HIF-1 $\alpha$ signaling $(41,42)$. Knockdown of p38 MAPK in the HER2-overexpressing MCF-7 cell line can inhibit $\mathrm{ALDH}^{+} \mathrm{CSCs}$, cancer cell migration and invasion $(43,44)$. In the present study, we demonstrated that doxycycline significantly decreased intracellular ROS levels, p38 MAPK phosphorylation and $\mathrm{ALDH}^{+} \mathrm{CSCs}$. Cancer cells treated with a p38 MAPK-specific inhibitor also exhibited a significant reduction in $\mathrm{ALDH}^{+} \mathrm{CSCs}$, indicating that doxycycline inhibited $\mathrm{ALDH}^{+} \mathrm{CSC}$ potentially via blocking the 
p38 MAPK signaling pathway. However, more evidence is needed to further support this hypothesis. Future studies will focus on directly investigating the involvement of p38 MAPK in doxycycline-mediated inhibition of $\mathrm{ALDH}^{+} \mathrm{CSCs}$. First, knockdown of p38 MAPK could be carried out in HER2 ${ }^{+}$and TNBC cell lines to ascertain whether $\mathrm{ALDH}^{+} \mathrm{CSC}$ population is affected. Second, a constitutively active p38 MAPK could be overexpressed to examine its ability to prevent or decrease doxycycline's effect on $\mathrm{ALDH}^{+} \mathrm{CSCs}$.

It is worth noting that doxycycline failed to inhibit $\mathrm{ALDH}^{+}$ CSC population and secondary mammosphere formation in SUM149 cells (Figs. 1C and 3B). The number of mammospheres formed is mainly determined by the number of stem cells seeded in the culture. The results, however, can be affected if the treatment changes the proliferation of cells. Therefore, to evaluate whether doxycycline can really affect CSCs, we performed the secondary mammosphere formation assays in the absence of doxycycline. Hence, the effect of doxycycline on proliferation was avoided, and the mammospheres should be decreased if the number of CSCs has been reduced by doxycycline in the primary assays. In SUM149 cells, we found that doxycycline significantly decreased primary but not secondary mammosphere formation. The reason may be that doxycycline inhibits cell proliferation (data not shown) instead of decreasing CSCs in SUM149 cells. In addition, SUM149 has been reported as an inflammatory breast cancer cell line that constitutively adapts to hypoxia $(45,46)$. Therefore, SUM149 can behave as if it is continuously hypoxic even under normoxia (45). This may explain why doxycycline decreases the ROS level but fails to inhibit $\mathrm{ALDH}^{+}$BCSCs in SUM149 cells.

Recent studies and our results indicate the potentiality of repurposing doxycycline, an old drug as a new treatment to target CSCs. Doxycycline is an FDA-approved antibiotic since 1960s. With limited toxicity to cells, doxycycline is relatively safe to be used concomitantly with chemotherapy drugs in patients (25). A recent clinical trial demonstrated that pathogenic bacteria-negative patients with lymphoma still benefit from doxycycline (47). More phase II clinical trials are ongoing to test the use of doxycycline as a CSC-targeting agent. In addition to targeting CSCs, doxycycline was also found to ameliorate tumor metastasis via inhibition of matrix metallopeptidases $(48,49)$. As such, we propose that doxycycline is an ideal drug that can be used in combination with cytotoxic chemotherapy drugs to eradicate both CSCs and bulk tumor cells.

\section{Acknowledgements}

The authors thank the Flow Cytometry Core of University of Michigan, supported by the NCI Grant P30CA046592 from the National Institutes of Health, for the technical support on flow cytometry work in this study.

\section{Funding}

No funding was received.

\section{Availability of data and materials}

The datasets used during the present study are available from the corresponding author upon reasonable request.

\section{Authors' contributions}

CCL conceived and designed the study and wrote the paper. CCL, RRM, NOS and SLT performed the experiments. MCL reviewed and edited the manuscript. MCL and DS supervised the research and manuscript preparation. All authors read and approved the manuscript and agree to be accountable for all aspects of the research in ensuring that the accuracy or integrity of any part of the work are appropriately investigated and resolved.

\section{Ethics approval and consent to participate}

Not applicable.

\section{Consent for publication}

Not applicable.

\section{Competing interests}

The authors declare that they have no competing interests.

\section{References}

1. Siegel R, Naishadham D and Jemal A: Cancer statistics, 2013. CA Cancer J Clin 63: 11-30, 2013.

2. Guiu S, Michiels S, André F, Cortes J, Denkert C, Di Leo A, Hennessy BT, Sorlie T, Sotiriou C, Turner N, et al: Molecular subclasses of breast cancer: How do we define them? The IMPAKT 2012 working group statement. Ann Oncol 23: 2997-3006, 2012.

3. Parker JS, Mullins M, Cheang MC, Leung S, Voduc D, Vickery T, Davies S, Fauron C, He X, Hu Z, et al: Supervised risk predictor of breast cancer based on intrinsic subtypes. J Clin Oncol 27: 1160-1167, 2009.

4. Lan KH, Lu CH and Yu D: Mechanisms of trastuzumab resistance and their clinical implications. Ann N Y Acad Sci 1059: 70-75, 2005.

5. Nahta R, Yu D, Hung MC, Hortobagyi GN and Esteva FJ: Mechanisms of disease: Understanding resistance to HER2-targeted therapy in human breast cancer. Nat Clin Pract Oncol 3: 269-280, 2006.

6. Yu KD, Zhu R, Zhan M, Rodriguez AA, Yang W, Wong S, Makris A, Lehmann BD, Chen X, Mayer I, et al: Identification of prognosis-relevant subgroups in patients with chemoresistant triple-negative breast cancer. Clin Cancer Res 19: 2723-2733, 2013.

7. Lapidot T, Sirard C, Vormoor J, Murdoch B, Hoang T, Caceres-Cortes J, Minden M, Paterson B, Caligiuri MA and Dick JE: A cell initiating human acute myeloid leukaemia after transplantation into SCID mice. Nature 367: 645-648, 1994.

8. Ginestier C, Hur MH, Charafe-Jauffret E, Monville F, Dutcher J, Brown M, Jacquemier J, Viens P, Kleer CG, Liu S, et al: ALDH1 is a marker of normal and malignant human mammary stem cells and a predictor of poor clinical outcome. Cell Stem Cell 1: 555-567, 2007.

9. Al-Hajj M, Wicha MS, Benito-Hernandez A, Morrison SJ and Clarke MF: Prospective identification of tumorigenic breast cancer cells. Proc Natl Acad Sci USA 100: 3983-3988, 2003.

10. Korkaya H, Kim GI, Davis A, Malik F, Henry NL, Ithimakin S, Quraishi AA, Tawakkol N, D'Angelo R, Paulson AK, et al: Activation of an IL6 inflammatory loop mediates trastuzumab resistance in HER2+ breast cancer by expanding the cancer stem cell population. Mol Cell 47: 570-584, 2012.

11. Zhou BB, Zhang H, Damelin M, Geles KG, Grindley JC and Dirks PB: Tumour-initiating cells: Challenges and opportunities for anticancer drug discovery. Nat Rev Drug Dis 8: 806-823, 2009.

12. Wicha MS: Targeting self-renewal, an Achilles' heel of cancer stem cells. Nat Med 20: 14-15, 2014. 
13. Hanahan D and Weinberg RA: Hallmarks of cancer: The next generation. Cell 144: 646-674, 2011.

14. Warburg O: The Metabolism of Tumor. Richard R. Smith, New York, 1931

15. Magda D, Lecane P, Prescott J, Thiemann P, Ma X, Dranchak PK, Toleno DM, Ramaswamy K, Siegmund KD and Hacia JG: mtDNA depletion confers specific gene expression profiles in human cells grown in culture and in xenograft. BMC Genomics 9: 521, 2008.

16. Morais R, Zinkewich-Péotti K, Parent M, Wang H, Babai F and Zollinger M: Tumor-forming ability in athymic nude mice of human cell lines devoid of mitochondrial DNA. Cancer Res 54 3889-3896, 1994.

17. Cavalli LR, Varella-Garcia M and Liang BC: Diminished tumorigenic phenotype after depletion of mitochondrial DNA. Cell Growth Differ 8: 1189-1198, 1997.

18. Weinberg F, Hamanaka R, Wheaton WW, Weinberg S, Joseph J, Lopez M, Kalyanaraman B, Mutlu GM, Budinger GR and Chandel NS: Mitochondrial metabolism and ROS generation are essential for Kras-mediated tumorigenicity. Proc Natl Acad Sci USA 107: 8788-8793, 2010.

19. Tan AS, Baty JW, Dong LF, Bezawork-Geleta A, Endaya B, Goodwin J, Bajzikova M, Kovarova J, Peterka M, Yan B, et al: Mitochondrial genome acquisition restores respiratory function and tumorigenic potential of cancer cells without mitochondrial DNA. Cell Metab 21: 81-94, 2015.

20. Farnie G, Sotgia F and Lisanti MP: High mitochondrial mass identifies a sub-population of stem-like cancer cells that are chemo-resistant. Oncotarget 6: 30472-30486, 2015.

21. Yan B, Stantic M,Zobalova R, Bezawork-Geleta A, Stapelberg M, Stursa J, Prokopova K, Dong L and Neuzil J: Mitochondrially targeted vitamin E succinate efficiently kills breast tumour-initiating cells in a complex II-dependent manner. BMC Cancer 15 401, 2015.

22. Pasdar EA, Smits M, Stapelberg M, Bajzikova M, Stantic M, Goodwin J, Yan B, Stursa J, Kovarova J, Sachaphibulkij K, et al: Characterisation of mesothelioma-initiating cells and their susceptibility to anti-cancer agents. PLoS One 10: e0119549, 2015.

23. LeBleu VS, O'Connell JT, Gonzalez Herrera KN, Wikman H, Pantel K, Haigis MC, de Carvalho FM, Damascena A, Domingos Chinen LT, Rocha RM, et al: PGC-1 $\alpha$ mediates mitochondrial biogenesis and oxidative phosphorylation in cancer cells to promote metastasis. Nat Cell Biol 16: 992-1003, 1-15, 2014.

24. Moullan N, Mouchiroud L, Wang X, Ryu D, Williams EG, Mottis A, Jovaisaite V, Frochaux MV, Quiros PM, Deplancke B, et al: Tetracyclines disturb mitochondrial function across eukaryotic models: A call for caution in biomedical research. Cell Rep: S2211-1247(15)00180-1, 2015.

25. Lamb R, Ozsvari B, Lisanti CL, Tanowitz HB, Howell A, Martinez-Outschoorn UE, Sotgia F and Lisanti MP: Antibiotics that target mitochondria effectively eradicate cancer stem cells, across multiple tumor types: Treating cancer like an infectious disease. Oncotarget 6: 4569-4584, 2015.

26. Lamb R, Fiorillo M, Chadwick A, Ozsvari B, Reeves KJ, Smith DL, Clarke RB, Howell SJ, Cappello AR, Martinez-Outschoorn UE, et al: Doxycycline down-regulates DNA-PK and radiosensitizes tumor initiating cells: Implications for more effective radiation therapy. Oncotarget 6: 14005-14025, 2015.

27. De Francesco EM, Maggiolini M, Tanowitz HB, Sotgia F and Lisanti MP: Targeting hypoxic cancer stem cells (CSCs) with Doxycycline: Implications for optimizing anti-angiogenic therapy. Oncotarget 8: 56126-56142,2017.

28. De Francesco EM, Bonuccelli G, Maggiolini M, Sotgia F and Lisanti MP: Vitamin C and Doxycycline: A synthetic lethal combination therapy targeting metabolic flexibility in cancer stem cells (CSCs). Oncotarget 8: 67269-67286, 2017.

29. Liu S, Cong Y, Wang D, Sun Y, Deng L, Liu Y, Martin-Trevino R, Shang L, McDermott SP, Landis MD, et al: Breast cancer stem cells transition between epithelial and mesenchymal states reflective of their normal counterparts. Stem Cell Reports 2: 78-91, 2013.

30. Brooks MD, Burness ML and Wicha MS: Therapeutic implications of cellular heterogeneity and plasticity in breast cancer. Cell Stem Cell 17: 260-271,2015.
31. Burnett JP, Korkaya H, Ouzounova MD, Jiang H, Conley SJ, Newman BW, Sun L, Connarn JN, Chen CS, Zhang N, et al: Trastuzumab resistance induces EMT to transform HER2 ${ }^{+}$ PTEN $^{-}$to a triple negative breast cancer that requires unique treatment options. Sci Rep 5: 15821, 2015.

32. Dontu G, Abdallah WM, Foley JM, Jackson KW, Clarke MF, Kawamura MJ and Wicha MS: In vitro propagation and transcriptional profiling of human mammary stem/progenitor cells. Genes Dev 17: 1253-1270, 2003.

33. Xu X, Chai S, Wang P, Zhang C, Yang Y, Yang Y and Wang K: Aldehyde dehydrogenases and cancer stem cells. Cancer Lett 369: 50-57, 2015.

34. Ahler E, Sullivan WJ, Cass A, Braas D, York AG, Bensinger SJ, Graeber TG and Christofk HR: Doxycycline alters metabolism and proliferation of human cell lines. PLoS One 8: e64561, 2013.

35. Samanta D, Gilkes DM, Chaturvedi P, Xiang L and Semenza GL: Hypoxia-inducible factors are required for chemotherapy resistance of breast cancer stem cells. Proc Natl Acad Sci USA 111: E5429-E5438, 2014.

36. Mani SA, Guo W, Liao MJ, Eaton EN, Ayyanan A, Zhou AY, Brooks M, Reinhard F, Zhang CC, Shipitsin M, et al: The epithelial-mesenchymal transition generates cells with properties of stem cells. Cell 133: 704-715, 2008 .

37. Liu S, Clouthier SG and Wicha MS: Role of microRNAs in the regulation of breast cancer stem cells. J Mammary Gland Biol Neoplasia 17: 15-21, 2012

38. Murphy MP: How mitochondria produce reactive oxygen species. Biochem J 417: 1-13, 2009.

39. Iriondo O, Rábano M, Domenici G, Carlevaris O, López-Ruiz JA, Zabalza I, Berra E and Vivanco M: Distinct breast cancer stem/progenitor cell populations require either HIF1 $\alpha$ or loss of PHD3 to expand under hypoxic conditions. Oncotarget 6: 31721-31739, 2015.

40. Conley SJ, Gheordunescu E, Kakarala P, Newman B, Korkaya H, Heath AN, Clouthier SG and Wicha MS: Antiangiogenic agents increase breast cancer stem cells via the generation of tumor hypoxia. Proc Natl Acad Sci USA 109: 2784-2789, 2012.

41. Gao N, Jiang BH, Leonard SS, Corum L, Zhang Z, Roberts JR, Antonini J, Zheng JZ, Flynn DC, Castranova V and Shi X: p38 signaling-mediated hypoxia-inducible factor lalpha and vascular endothelial growth factor induction by $\mathrm{Cr}(\mathrm{VI})$ in DU145 human prostate carcinoma cells. J Biol Chem 277: 45041-45048, 2002.

42. Kwon SJ, Song JJ and Lee YJ: Signal pathway of hypoxia-inducible factor-1alpha phosphorylation and its interaction with von Hippel-Lindau tumor suppressor protein during ischemia in MiaPaCa-2 pancreatic cancer cells. Clin Cancer Res 11: 7607-7613, 2005.

43. Xu M, Ren Z, Wang X, Comer A, Frank JA, Ke ZJ, Huang Y, Zhang Z, Shi X, Wang S and Luo J: ErbB2 and p38gamma MAPK mediate alcohol-induced increase in breast cancer stem cells and metastasis. Mol Cancer 15: 52, 2016.

44. Xu M, Wang S, Ren Z, Frank JA, Yang XH, Zhang Z, Ke ZJ, Shi $X$ and Luo J: Chronic ethanol exposure enhances the aggressiveness of breast cancer: The role of p38 $\gamma$. Oncotarget 7: 3489-3505, 2016.

45. Silvera D and Schneider RJ: Inflammatory breast cancer cells are constitutively adapted to hypoxia. Cell Cycle 8: 3091-3096, 2009.

46. Wynn ML, Yates JA, Evans CR, Van Wassenhove LD, Wu ZF, Bridges S, Bao L, Fournier C, Ashrafzadeh S, Merrins MJ, et al: RhoC GTPase is a potent regulator of glutamine metabolism and $\mathrm{N}$-acetylaspartate production in inflammatory breast cancer cells. J Biol Chem 291: 13715-13729, 2016.

47. Ferreri AJ, Ponzoni M, Guidoboni M, Resti AG, Politi LS, Cortelazzo S, Demeter J, Zallio F, Palmas A, Muti G, et al: Bacteria-eradicating therapy with doxycycline in ocular adnexal MALT lymphoma: A multicenter prospective trial. J Natl Cancer Inst 98: 1375-1382, 2006

48. Shen LC, Chen YK, Lin LM and Shaw SY: Anti-invasion and anti-tumor growth effect of doxycycline treatment for human oral squamous-cell carcinoma-in vitro and in vivo studies. Oral Oncol 46: 178-184, 2010.

49. Duivenvoorden WC, Popović SV, Lhoták S, Seidlitz E, Hirte HW, Tozer RG and Singh G: Doxycycline decreases tumor burden in a bone metastasis model of human breast cancer. Cancer Res 62: 1588-1591, 2002. 